\title{
The longitudinal effect of subclinical hypothyroidism on urine microalbumin-to- urine creatinine ratio in patients with type 2 diabetes mellitus
}

\author{
Juan Xie ${ }^{\dagger}$, Xiaoqing Wang ${ }^{\dagger}$, Yiyuan Zhang, Hailun Li, Yong Xu* and Donghui Zheng ${ }^{*}$
}

\begin{abstract}
Background: In patients with diabetes mellitus, the urinary microalbumin-to-urine creatinine ratio (UACR) can not only predict the occurrence of diabetic nephropathy but also can be a risk factor for cardiovascular disease and renal function damage. Current studies on subclinical hypothyroidism $(\mathrm{SCH})$ and UACR are mainly cross-sectional studies, and the results suggest that $\mathrm{SCH}$ is an independent risk factor for UACR. To further explore the longitudinal effect of SCH on UACR, we carried out this study.

Methods: This was a retrospective cohort study including 46 patients with type 2 diabetes mellitus and SCH in the Department of Endocrinology, The Affiliated Huai'an Hospital of Xuzhou Medical University from January 2013 to April 2018. At the same time, 96 patients with type 2 diabetes mellitus and euthyroid were chosen according to 1:2 approximately matched with age, sex and duration of diabetes mellitus. Univariate analysis, stratified analysis, and multiple linear regression analysis were used to investigate the effect of SCH on $\triangle \cup A C R(\triangle U A C R=U A C R$ after 1 year baseline UACR) in patients with type 2 diabetes mellitus.
\end{abstract}

Results: There was no significant difference between the baseline UACR, $(p>0.05)$. However, the $\triangle U A C R$ was significantly higher in $\mathrm{SCH}$ group than euthyroid group, as shown by univariate analysis, stratified analysis and multiple linear regression analysis (B:-1.071, 95\% Cl: $-1.713--0.428)$, and the difference was statistically significant (all $p<0.05)$.

Conclusion: SCH is associated with an increased UACR in type 2 diabetes mellitus patients. It is necessary to screen for thyroid function in type 2 diabetes mellitus and increase the follow-up frequency of UACR in patients with SCH.

Keywords: Subclinical hypothyroidism, Type 2 diabetes mellitus, Urine microalbumin-to-urine creatinine ratio

\section{Background}

Subclinical hypothyroidism $(\mathrm{SCH})$ is an endocrine disorder characterized by elevated serum thyroid stimulating hormone (TSH) levels and normal thyroid hormone (T4) and triiodothyronine (T3) concentrations. The prevalence of $\mathrm{SCH}$ is approximately $5 \%$ in the general population [1-3], but is higher in type 2 diabetes mellitus (T2DM), the reported SCH levels in DM is roughly 10\% [4-6]. Higher morbidity is related to age, being female and iodine intake [7]. SCH is an early mild hypothyroidism that can develop

\footnotetext{
*Correspondence: haeyxy@163.com; zddwjj@126.com

†Juan Xie and Xiaoqing Wang contributed equally to this work.

The Affiliated Huai'an Hospital of Xuzhou Medical University, Huaian 223002, Jiangsu, China
}

(c) The Author(s). 2019 Open Access This article is distributed under the terms of the Creative Commons Attribution 4.0 International License (http//creativecommons.org/licenses/by/4.0/) which permits unrestricted use distribution, and reproduction in any medium, provided you give appropriate credit to the original author(s) and the source, provide a link to the Creative Commons license, and indicate if changes were made. The Creative Commons Public Domain Dedication waiver (http://creativecommons.org/publicdomain/zero/1.0/) applies to the data made available in this article, unless otherwise stated.

into clinical hypothyroidism, which is a risk factor for atherosclerosis, heart failure, atrial fibrillation, stroke, and renal dysfunction $[8,9]$.

Urinary microalbumin-to-urine creatinine ratio (UACR) is an important predictor of diabetic nephropathy, and independent risk factor for cardiovascular disease and represents endothelial dysfunction in DM, even within the normal range [10, 11]. A number of cross-sectional clinical investigations suggest that patients with $\mathrm{DM}$ and $\mathrm{SCH}$ have higher urinary microalbumin levels than those with normal thyroid function [12-14], high TSH was significantly associated with microalbuminuria even in diabetic patients with euthyroid [15]. The longitudinal effect of SCH on UACR in patients with type 2 diabetes mellitus is still unclear. We 
retrospectively analyzed the effect of $\mathrm{SCH}$ on the $\triangle \mathrm{UACR}$ $(\triangle \mathrm{UACR}=\mathrm{UACR}$ after 1 year - baseline UACR $)$ in patients with T2DM to provide a theoretical basis for the follow-up and treatment of SCH in T2DM, which may delay the occurrence and progression of diabetic nephropathy and improve the long-term prognosis of patients.

\section{Methods \\ Patients}

This is a retrospective cohort study using data from Electronic Medical Record System of The Affiliated Huai'an Hospital of Xuzhou Medical University. From January 2013 to April 2018, 46 patients with T2DM and SCH were recruited. At the same time, 96 patients with T2DM and euthyroid were chosen according to 1:2 approximately, who were matched with regards to age, sex and duration of DM. Subjects with age $\geq 18$ years old, a diagnosis of T2DM, and have complete clinical data were included. The exclusion criteria were (1) history of thyroid diseases, or taking levothyroxine tablets (2) stage 4-5 chronic renal failure, (3) glomerulonephritis, (4) liver dysfunction, (5) severe infection, (6) connective tissue disease, (7) malignant tumor, (8) pregnancy, (9) women taking contraceptives or hormone replacement therapy, (10) uncontrolled hypertension, (11)congestive heart failure and (12) amiodarone or lithium preparations. The diagnosis of DM was based on the criteria of the 1999 WHO criteria, and the diagnosis of SCH was persistently elevated TSH values (at least twice, at least 3 months apart) with FT4 levels within the reference range, exclusion of previous thyroid disease.

\section{Data collection}

Patient baseline data were obtained from Electronic Medical Record System, included age, gender, height, body weight, blood pressure, history of hypertension, duration of T2DM, total cholesterol (TC), triglycerides (TG), highdensity lipoprotein cholesterol (HDL-C), low-density lipoprotein cholesterol (LDL-C), serum creatinine, blood urea nitrogen, glycosylated hemoglobin (HbA1c), FT4, FT3, $\mathrm{TSH}$, and UACR. After 1 year, the patients were readmitted to the hospital, and we collected all the informations above.

\section{Laboratory measurements}

Blood specimens were tested in the central laboratory and urine specimens in the nephropathy laboratory. UACR was measured from a single voided urine sample by Nephropathy Laboratory. Detection of TSH, FT3 and FT4 by chemiluminescent particle immunoassay (Abbot, America, i2000SR). The reference ranges of thyroid function test in our hospital: TSH $0.35-5.0 \mathrm{mU} / \mathrm{ml}$; FT3 2.75-6.8 pmol/L, FT4 7.5-22 pmol/L. Urinary creatinine was detected by enzymatic method(SIEMENS, Germany, BNProSpec); urinary albumin was detected by scattering turbidimetry(Abbot, America,c16000).

\section{Related definitions}

Glycemic control: According to the guidelines for good glycemic control, the glycosylated hemoglobin (HbA1c) level should be controlled at a level of $<7 \%$ for most patients with T2DM, poor control of glycemic was considered when HbA1c $>7 \%[16,17]$. BMI: $\mathrm{BMI}<23.9$ was

Table 1 Baseline characteristics of study participants

\begin{tabular}{|c|c|c|c|}
\hline Characteristic & $\mathrm{SCH}(n=46)$ & Euthyroid $(n=96)$ & $P$-value \\
\hline Gender (male/female) ${ }^{b}$ & $23 / 23$ & $49 / 47$ & 0.91 \\
\hline Duration of T2DM (years) ${ }^{a}$ & $12.74 \pm 10.40$ & $11.63 \pm 6.79$ & 0.45 \\
\hline History of hypertension (have/none) ${ }^{b}$ & $15 / 31$ & $25 / 71$ & 0.42 \\
\hline BMI $\left(\mathrm{kg} / \mathrm{m}^{2}\right)^{\mathrm{a}}$ & $25.14 \pm 2.86$ & $25.21 \pm 2.98$ & 0.89 \\
\hline $\mathrm{TC}(\mathrm{mmol} / \mathrm{L})^{\mathrm{a}}$ & $2.08 \pm 1.15$ & $2.13 \pm 2.69$ & 0.90 \\
\hline TG $(\mathrm{mmol} / \mathrm{L})^{\mathrm{a}}$ & $4.20 \pm 0.98$ & $4.37 \pm 1.56$ & 0.51 \\
\hline $\mathrm{HDL}-\mathrm{C}(\mathrm{mmol} / \mathrm{L})^{\mathrm{a}}$ & $1.09 \pm 0.30$ & $1.17 \pm 0.29$ & 0.10 \\
\hline LDL-C (mmol/L $)^{a}$ & $2.18 \pm 0.66$ & $2.29 \pm 0.72$ & 0.38 \\
\hline Baseline creatinine $(\mu \mathrm{mol} / \mathrm{L})^{\mathrm{b}}$ & $77.80 \pm 27.19$ & $67.25 \pm 17.66$ & 0.01 \\
\hline Baseline eGFR (ml/min) ${ }^{b}$ & $90.49 \pm 35.04$ & $103.03 \pm 32.26$ & 0.04 \\
\hline Baseline UACR $(\mathrm{mg} / \mathrm{mmol})^{\mathrm{b}}$ & $4.82 \pm 8.38$ & $3.68 \pm 6.25$ & 0.64 \\
\hline $\mathrm{TSH}(\mu \mathrm{IU} / \mathrm{ml})^{\mathrm{b}}$ & $8.57 \pm 6.31$ & $2.09 \pm 0.96$ & 0.00 \\
\hline FT3 $(\mathrm{mU} / \mathrm{mll})^{\mathrm{b}}$ & $4.12 \pm 0.88$ & $4.42 \pm 0.70$ & 0.03 \\
\hline $\mathrm{FT} 4(\mathrm{mU} / \mathrm{ml})^{\mathrm{b}}$ & $17.61 \pm 14.66$ & $16.71 \pm 2.49$ & 0.68 \\
\hline
\end{tabular}

${ }^{a}$, Expressed as the means \pm standard deviation (SD), the comparison of continuous data was achieved by $t$-test or rank sum test; ${ }^{b}$, Described in percentage form. The classification data were compared with $X^{2}$ test. SCH subclinical hypothyroidism,T2DM type 2 diabetes mellitus, BMI body mass index, eGFR estimated glomerular filtration rate, $U A C R$ urinary microalbumin-to-urine creatinine ratio, $T C$ total cholesterol, $T G$ triglyceride, $H D L-C$ high-density lipoprotein cholesterol, $L D L-$ C low-density lipoprotein cholesterol, TSH thyroid stimulating hormone, FT4 free thyroid hormone, FT3 triiodothyronine 
Table 2 Univariate analysis for $\triangle U A C R$ in patients with T2DM

\begin{tabular}{llll}
\hline Group & Median & P25-P75 & $P$-value \\
\hline SCH & 1.07 & $(-0.02,6.34)$ & $<0.001$ \\
Euthyroid & 0.00 & $(-0.68,0.60)$ & \\
\hline
\end{tabular}

Analysis is achieved by rank sum test

defined normal, BMI $>24.0$ was defined overweight or obesity.

\section{Medical formulas}

UACR $(\mathrm{mg} / \mathrm{mmol})=$ urinary albumin $(\mathrm{mg} / \mathrm{L}) /$ urinary creatinine $(\mathrm{mmol} / \mathrm{L}) . \triangle \mathrm{UACR}=\mathrm{UACR}$ after 1 year - the baseline UACR. Body mass index (BMI) was derived as weight $(\mathrm{kg}) /$ height $(\mathrm{m})^{2}$. Estimated glomerular filtration rate $(\mathrm{eGFR})\left[\mathrm{mL} /\left(\mathrm{min} \cdot 1.73 \mathrm{~m}^{2}\right)\right]=186 \times \mathrm{Scr}(\mathrm{mg} / \mathrm{dL})^{-1.154} \times$ age $^{-0.203}(\times 0.742$ female $)$.

\section{Statistical analysis}

All statistical tests were analyzed by SPSS version 23.0. The quantitative normal distribution data were expressed as the means \pm standard deviation (SD), and the classification data were described in percentage form. The comparison of continuous data was achieved by $t$-test or rank sum test, and the classification data were compared with $X^{2}$ test. Univariate analysis, stratified analysis and multiple linear regression analysis were used to explore the effect of SCH on $\triangle \mathrm{UACR}$. A two-sided $p$-value $<0.05$ was considered to be statistically significant.

\section{Results}

The baseline characteristics of study patients are presented in Table 1. Patients with SCH had higher creatinine, lower
e-GFR, higher TSH, lower TG and FT3 than euthyroid patients(all $P<0.05$ ). There were no significant differences in gender, age, duration of DM, history of hypertension, BMI, FT4, TC, HDL-C and LDL-C, baseline UACR between the two groups (all $P>0.05$ ).

The longitudinal effect of $\mathrm{SCH}$ on UACR in patients with type 2 diabetes mellitus: 1 . Univariate analysis: The $\triangle \mathrm{UACR}$ in the SCH group was higher than in the euthyroid group, and the difference was statistically significant $(P<0.001)$, (Table 2). 2.Stratified analysis: When stratified according to sex (male/female), duration of diabetes (duration $\leq 10$ years/duration $>10$ years), BMI $\left(\mathrm{BMI}<24 \mathrm{~kg} / \mathrm{m}^{2} /\right.$ BMI $>24 \mathrm{~kg} / \mathrm{m}^{2}$ ), control of glycemic (well/poor), history of hypertension (have/none), the $\triangle \mathrm{UACR}$ of the $\mathrm{SCH}$ group was higher than euthyroid group. The difference was statistically significant $(p<0.01)$, (Table 3$)$. 3. Multivariate analysis: After converting the absolute value of $\triangle \mathrm{UACR}$ to logarithm, it obeyed normal distribution. The BMI (1 was normal; 2 as overweight and obesity), control of glycemic (1 was well controlled; 2 was poorly controlled), the duration of diabetes mellitus ( 1 for 10 years or less; 2 for more than 10 years), age ( 1 for 18 to 65 years; 2 for 66 to 75 years, 3 for more than 75 years) were controlled, using multiple linear regression analysis of the effect of $\mathrm{SCH}$ on $\triangle \mathrm{UACR}$. The results showed that $\triangle \mathrm{UACR}$ in the $\mathrm{SCH}$ group was still statistically significant compared with that in the control group $(p<0.01)$ (Table 4$)$.

\section{Discussion}

Thyroid dysfunction and T2DM are the two most common diseases observed in the Department of Endocrinology. Studies have shown that the prevalence of thyroid diseases

Table 3 Stratified analysis for $\triangle U A C R$ in patients with T2DM

\begin{tabular}{|c|c|c|c|}
\hline stratified factors & Euthyroid M (Q) & $\mathrm{SCH} M(\mathrm{Q})$ & $P$-value ${ }^{\&}$ \\
\hline \multicolumn{4}{|l|}{ Gender } \\
\hline male & $0.10(-0.40,1.20)$ & $1.20(0.00,6.62)$ & $<0.01$ \\
\hline female & $-0.20(-0.74,0.30)$ & $0.80(-0.10,6.24)$ & $<0.01$ \\
\hline \multicolumn{4}{|l|}{$\mathrm{BMI}\left(\mathrm{kg} / \mathrm{m}^{2}\right)$} \\
\hline normal & $0.25(-0.49,1.75)$ & $1.140(0.40,16.75)$ & $<0.01$ \\
\hline overweight or obesity & $-0.10(-0.73,0.27)$ & $1.00(-0.09,5.96)$ & $<0.01$ \\
\hline \multicolumn{4}{|l|}{ Duration of T2DM (years) } \\
\hline$\sim 10$ & $-0.10(-0.71,0.38)$ & $1.17(-0.03,12.13)$ & $<0.01$ \\
\hline $11 \sim$ & $0.04(-0.56,0.93)$ & $0.75(-0.02,6.34)$ & $<0.01$ \\
\hline \multicolumn{4}{|l|}{ Control of glycemic } \\
\hline well & $0.00(-0.60,0.60)$ & $1.40(0.18,5.68)$ & $<0.01$ \\
\hline poor & $0.00(-0.73,0.65)$ & $0.84(-0.08,7.47)$ & $<0.01$ \\
\hline \multicolumn{4}{|l|}{ History of hypertension } \\
\hline have & $-0.10(-0.75,1.23)$ & $0.90(0.00,4.60)$ & $<0.01$ \\
\hline none & $0.00(-0.50,0.39)$ & $1.20(-0.07,10.00)$ & $<0.01$ \\
\hline
\end{tabular}

$M$ median, $Q$ interquartile range (P25,P75); \&, Analysis is achieved by rank sum test, $B M I$ body mass index; HbAlc $<7 \%$ was better glycemic controlled; HbAlc $>7 \%$ was poor glycemic controlled; $\mathrm{BMI}<23.9$ was defined normal; $\mathrm{BMI}>24.0$ was defined overweight or obesity 
Table 4 Multivariate analysis for $\triangle U A C R$ in patients with T2DM

\begin{tabular}{llllll}
\hline & $\beta$ & SD & $P$-value & \multicolumn{2}{c}{$95 \% \mathrm{Cl}$} \\
Group & -1.07 & 0.33 & 0.00 & -1.71 & -0.43 \\
\hline BMl & -0.66 & 0.33 & 0.05 & -1.32 & -0.00 \\
Control of glycemic & 0.19 & 0.331 & 0.561 & -0.46 & 0.85 \\
Duration of T2DM & -0.25 & 0.30 & 0.42 & -0.85 & 0.35 \\
Age & -0.05 & 0.19 & 0.78 & -0.44 & 0.33 \\
Constant term & 2.80 & 1.14 & 0.02 & 0.54 & 5.07
\end{tabular}

After converting the absolute value of $\triangle U A C R$ to logarithm, it obeyed normal distribution, the absolute value of UACR was used to analysis. SD standard deviation, T2DM type 2 diabetes mellitus, $B M I$ body mass index

is significantly higher in patients with DM than healthy people, and $\mathrm{SCH}$ at the first list $[7,18]$. SCH can be seen as mild thyroid failure [19], and although most $\mathrm{SCH}$ patients have no obvious symptoms, they are more likely to suffer from depression, fatigue, muscle weakness, cold tolerance, and quality of life, cognitive function and memory decline than healthy people [20]. Several studies showed that subclinical hypothyroidism is associated with dyslipidemia, hypertension, accelerated atherosclerosis, and coronary artery disease, heart failure, lower renal function [21-24].

Yasuda T.et al. reported that $\mathrm{SCH}$ is independently associated with albuminuria in patients with T2DM on the cross section [12]. Subsequently several studies have come to the same conclusion $[25,26]$, which suggests that subclinical hypothyroidism may have an impact on urinary microalbumin. In this study, the $\triangle \mathrm{UACR}$ in the $\mathrm{SCH}$ group was statistically significant, whether in univariate analysis, stratified analysis or multivariate analysis. Our study further suggests that $\mathrm{SCH}$ has an effect on UACR in patients with T2DM and promotes the progress of UACR. As far as we know, this is the first study about the effect of $\mathrm{SCH}$ on the 1-year change UACR in patients with T2DM.

The mechanism of $\mathrm{SCH}$ affecting UACR in patients with T2DM is unclear. The possible mechanisms are as follows. Hypothyroidism and $\mathrm{SCH}$ are related to insulin sensitivity and impaired glucose tolerance, and the ability of insulin to utilize glucose in muscle decreases [27]. The downregulation of glucose transporter protein directly affects the degradation of insulin [28]. Second, some studies suggest that endothelial dysfunction occurs in patients with $\mathrm{SCH}$ due to endothelium-dependent vasodilation dysfunction and NO utilization disorder, and this phenomenon still independently appears after correcting lipid disorders and levothyroxine treatment [29].

In this study, the sample size of patients was small. The control group was matched for age, gender, and duration of DM, so there may be case selection bias. To reduce selection bias, the hospitalization number of patients with T2DM with euthyroid was randomized, and 96 patients were selected as a control group using a randomization tool after calculating the sample size of the control group. The specific mechanism of subclinical hypothyroidism affecting UACR in patients with T2DM is still unclear, and further basic research is needed.

\section{Conclusions}

$\mathrm{SCH}$ has a significant impact on UACR in patients with T2DM. It is necessary to screen for thyroid function in patients with T2DM. At the same time, we need to increase the frequency of follow-up of UACR in patients with T2DM and $\mathrm{SCH}$, with timely intervention if necessary, to improve the prognosis of patients.

\section{Abbreviations \\ ADA: American Diabetes Association; BMI: Body mass index; eGFR: Estimated glomerular filtration rate; FT3: Triiodothyronine; FT4: Free thyroid hormone; HbA1c: Glycosylated hemoglobin; HDL-C: High-density lipoprotein cholesterol; LDL-C: Low-density lipoprotein cholesterol; SCH: Subclinical hypothyroidism; SD: Standard deviation; T2DM: Type 2 diabetes mellitus; TC: Total cholesterol; TG: Triglyceride; TSH: Thyroid stimulating hormone; UACR: Urinary microalbumin-to-urine creatinine ratio}

\section{Acknowledgments}

We acknowledge the Department of Endocrinology, The Affiliated Huai'an Hospital of Xuzhou Medical University workers for their cooperation and permission to conduct the study. We are also thankful to patients who provide case information.

\section{Authors' contributions}

$J X, X Q W, Y X$ and $D H Z$ were responsible for conception, design of the study, acquisition, analysis and interpretation of data. YYZ, HLL drafted the article and revised contents. All authors have read and approved the final version of the manuscript.

\section{Funding}

This study was funded by "Supported Project of Jiangsu Post-doctoral Research.Grant Program" in 2018(Grant number 2018K078B). The funder had no role on the study design, data analysis, interpretation and writing the manuscript in this study.

\section{Availability of data and materials}

Patients' information are not publicly available due to restrictions imposed by China law, is may be obtained from hospital electronic medical record system on reasonable request and if legal implications are fulfilled. The names of patients were not registered in our data and their unique ID numbers were locked for confidentiality.

\section{Ethics approval and consent to participate}

All procedures performed in studies were in accordance with the ethical standards of the institutional and/or national research committee and with the 1964 Helsinki declaration and its later amendments or comparable ethical standards. The study was approved by The Affiliated Huai'an Hospital of Xuzhou Medical University (Approval No HEYLL201637). Informed consent was waived by the local ethics committee due retrospective nature of analysis with no impact on health outcome.

\section{Consent for publication}

Not applicable

Competing interests

The authors declare that they have no competing interests. 
Received: 26 November 2018 Accepted: 10 July 2019

Published online: 05 August 2019

\section{References}

1. Garmendia MA, Santos PS, Guillen-Grima F, Galofre JC. The incidence and prevalence of thyroid dysfunction in Europe: a meta-analysis. J Clin Endocrinol Metab. 2014:99(3):923-31.

2. Epidemiological Study on Subclinical Hypothyroidism in Different Populations in China: Harbin Medical University; 2012.

3. Grg A, Gorgulho B, Lotufo PA, Bensenor IM, Marchioni DM. Dietary selenium intake and subclinical hypothyroidism: a cross-sectional analysis of the ELSA-Brasil study. NUTRIENTS. 2018;10(6):693.

4. Qi Q, Zhang QM, Li CJ, Dong RN, Li JJ, Shi JY, Yu DM, Zhang JY. Association of Thyroid-Stimulating Hormone Levels with microvascular complications in type 2 diabetes patients. Med Sci Monit. 2017:23:2715-20.

5. Han C, He X, Xia X, Li Y, Shi X, Shan Z, Teng W. Subclinical hypothyroidism and type 2 diabetes: a systematic review and meta-analysis. PLoS One. 2015;10(8):e135233.

6. Diez JJ, Sanchez P, Iglesias P. Prevalence of thyroid dysfunction in patients with type 2 diabetes. Exp Clin Endocrinol Diabetes. 2011;119(4):201-7.

7. Ozair M, Noor S, Raghav A, Siddiqi SS, Chugtai AM, Ahmad J. Prevalence of thyroid disorders in North Indian Type 2 diabetic subjects: A cross sectional study. Diabetes Metab Syndr. 2018;12:301-304

8. Rosario PW. Subclinical hypothyroidism. New Engl J Med. 2017;377(14):1404.

9. Moon S, Kim MJ, Yu JM, Yoo HJ, Park YJ. Subclinical hypothyroidism and the risk of cardiovascular disease and all-cause mortality: a meta-analysis of prospective cohort studies. Thyroid. 2018;28:1101-10.

10. Marcovecchio ML, Chiesa ST, Armitage J,Daneman D, Donaghue KC, Jones TW, Mahmud FH, Marshall SM, Haw N, Dalton RN. Renal and cardiovascular risk according to tertiles of urinary albumin-to-creatinine ratio: the adolescent type 1 diabetes cardio-renal intervention trial (AdDIT). Diabetes Care. 2018;41:1963-69.

11. Scirica BM, Mosenzon O, Bhatt DL, Udell JA, Steg PG, Mcquire DK, Im K, Kanevsky E, Stahre C, Sjöstrand M. Cardiovascular outcomes according to urinary albumin and kidney disease in patients with type 2 diabetes at high cardiovascular risk: observations from the SAVOR-TIMI 53 trial. JAMA Cardiol. 2018;3:155-63.

12. Yasuda T, Kaneto H, Kuroda A, Yamamoto T, Takahara M, Naka T, Miyashita K, Fujisawa K, Sakamoto F, Katakami N. Subclinical hypothyroidism is independently associated with albuminuria in people with type 2 diabetes. Diabetes Res Clin Pract. 2011;94(3):e75-7.

13. Mansournia N, Riyahi S, Tofangchiha S, Mansournia MA, Riahi M, Heidari Z, Hazrati E. Subclinical hypothyroidism and diabetic nephropathy in Iranian patients with type 2 diabetes. J Endocrinol Investig. 2017;40(3):1-7.

14. El-Eshmawy MM, Abd El-Hafez HA, El Shabrawy WO, Abdel Aal IA. Subclinical hypothyroidism is independently associated with microalbuminuria in a cohort of Prediabetic Egyptian adults. Diabetes Metab J. 2013;37(6):450-7.

15. Das G. Peter N Taylor, Hussam Abusahmin1, Amer Ali1, Brian P Tennant, John Geen, Onyebuchi Okosieme:relationship between serum thyrotropin and urine albumin excretion in euthyroid subjects with diabetes. Ann Clin Biochem. 2019;56:155-62.

16. Nathan DM, Buse JB, Davidson MB, Ferrannini E, Holman RR, Sherwin R, Zinman B. Medical management of hyperglycemia in type 2 diabetes: a consensus algorithm for the initiation and adjustment of therapy: a consensus statement of the American Diabetes Association and the European Association for the Study of diabetes. Diabetes Care. 2009;32(1):193-203.

17. Geriatric Endocrinology and Metabolism Branch of the Chinese Geriatrics Society, National Clinical Research Center of Geriatric Diseases (Chinese PLA General Hospital). Compilation group of Expert Consensus of the Diagnosis and Treatment Measures for the Chinese Elderly Patients with Type 2 Diabetes. Expert consensus of the diagnosis and treatment measures for the Chinese elderly patients with type 2 diabetes (2018 Edition). Chin J Integr Med. 2018;57(9):626-41.

18. Fleiner HF, Bjøro T, Midthjell K, Grill V, Bo A. Prevalence of thyroid dysfunction in autoimmune and type 2 diabetes. The population-based HUNT study in Norway. J Clin Endocrinol Metab. 2016;101(2):669-77.

19. Biondi B. Natural history, diagnosis and management of subclinical thyroid dysfunction. Best Pract Res Clin Endocrinol Metab. 2012;26(4):431-46.

20. Quinn TJ, Gussekloo J, Kearney P, Rodondi N, Stott DJ. Subclinical thyroid disorders : the Lancet. Lancet. 2012;380(9839):335-6.
21. Tuliani TA, Shenoy M, Belgrave K, Deshmukh A, Pant S, Hilliard A, Afonso L. Role of microalbuminuria in predicting cardiovascular mortality in individuals with subclinical hypothyroidism. Am J Med Sci. 2017;354(3):285-90.

22. Palmieri EA, Fazio S, Lombardi G, Biondi B. Subclinical hypothyroidism and cardiovascular risk. Treat Endocrinol. 2004;3(4):233-44.

23. Gopinath B, Harris DC, Wall JR, Kifley A, Mitchell P. Relationship between thyroid dysfunction and chronic kidney disease in community-dwelling older adults. Maturitas. 2013;75(2):159-64.

24. Chang YC, Chang CH, Yeh YC, Chuang LM, Tu YK. Subclinical and overt hypothyroidism is associated with reduced glomerular filtration rate and proteinuria: a large cross-sectional population study. Sci Rep. 2018:8(1):2031

25. Furukawa S, Yamamoto S, Todo Y, Maruyama K, Miyake T, Ueda T, Niiya T, Senba T, Torisu M, Kumagi T. Association between subclinical hypothyroidism and diabetic nephropathy in patients with type 2 diabetes mellitus. Endocr J. 2014;61(10):1011-8.

26. Mansournia N, Riyahi S, Tofangchiha S, Mansournia MA, Riahi M, Heidari Z, Hazrati E. Subclinical hypothyroidism and diabetic nephropathy in Iranian patients with type 2 diabetes. J Endocrinol Investig. 2017;40(3):289-95.

27. Dimitriadis G, Mitrou P, Lambadiari V, Boutati E, Maratou E, Panagiotakos DB, Koukkou E, Tzanela M, Thalassinos N, Raptis SA. Insulin action in adipose tissue and muscle in hypothyroidism. J Clin Endocrinol Metab. 2006;91(12):4930-7.

28. Maratou E, Hadjidakis DJ, Kollias A, Tsegka K, Peppa M, Alevizaki M, Mitrou P, Lambadiari V, Boutati E, Nikzas D. Studies of insulin resistance in patients with clinical and subclinical hypothyroidism. Eur J Endocrinol. 2009:160(5):785-90.

29. Biondi B, Galderisi M, Pagano L, Sidiropulos M, Pulcrano M, D’ errico A, Ippolito S, Rossi A, De DO, Lombardi G. Endothelial-mediated coronary flow reserve in patients with mild thyroid hormone deficiency. Eur J Endocrinol. 2009;161(2):323-9.

\section{Publisher's Note}

Springer Nature remains neutral with regard to jurisdictional claims in published maps and institutional affiliations.

Ready to submit your research? Choose BMC and benefit from:

- fast, convenient online submission

- thorough peer review by experienced researchers in your field

- rapid publication on acceptance

- support for research data, including large and complex data types

- gold Open Access which fosters wider collaboration and increased citations

- maximum visibility for your research: over $100 \mathrm{M}$ website views per year

At BMC, research is always in progress.

Learn more biomedcentral.com/submissions 